\title{
Clinical Reasoning: A middle-aged man with new onset seizures and myoclonic jerks
}

Zhiyong Chen, MBBS, MRCP, and Shermyn Neo, MBBS, MRCP

Neurology ${ }^{\circledR}$ 2019;92:e274-e281. doi:10.1212/WNL.0000000000006781

Correspondence

Dr. Chen

chen.zhiyong@

singhealth.com.sg

\section{Section 1}

A 53-year-old man with a history of hypertension presented with new-onset seizures. On the day of admission, he was witnessed by his son to have right-sided jerking that lasted for 1 minute, after which he fell forward and lost consciousness. He was disoriented, drowsy, and only regained full consciousness in the ambulance. Occasional jerks of the right upper limb had been observed while the patient was writing and performing daily activities for 2 days prior to the event. He also complained of $10 \mathrm{~kg}$ of unintentional weight loss over a period of 2 months with no other systemic complaints.

On neurologic examination on the day of admission, the patient was alert and fully oriented with no obvious cortical deficits. Cranial nerves were intact; tone, deep tendon reflexes, power, and sensation were normal. On action and on posture, there were intermittent distal right upper limb myoclonic jerks. They were not present at rest and not associated with startle. There were no cerebellar signs.

On the second day of admission, the patient was observed to have forced head turn to the right as well as right upper limb dystonic posturing, which lasted for 2 minutes before being aborted by IV diazepam.

\section{Question for consideration:}

1. What is the localization of the lesion?

GO TO SECTION 2 


\section{Section 2}

The patient in this vignette presented with new-onset complex partial seizures as well as focal myoclonus. Seizure semiology as well as phenomenology of the myoclonus can help with lesion localization.

Features in seizure semiology can help to lateralize the side of seizure origin. Both dystonic limb posturing and late forced head version localizes the focus to the contralateral cerebral cortex. Dystonic posturing has an especially high specificity in terms of lesion lateralization.

Myoclonic jerks are sudden, brief, shock-like movements. Myoclonic jerks are characterized by their distribution, rhythmicity, and whether the jerks occur spontaneously or if they demonstrate sensitivity to action or stimulus. Cortical myoclonus typically involves the face and distal extremities, is usually triggered by action, and is often stimulus-sensitive. It is typically nonrhythmic, although in the setting of epilepsia partialis continua, jerks may appear rhythmic.

Focal cortical myoclonus almost always points to an underlying lesion of the motor cortex, which results in hyperexcitability. ${ }^{1}$ The myoclonic jerks of the patient in the vignette suggest focal cortical myoclonic jerks; this is likely localized to the area representing the upper limb in the primary motor cortex.

\section{Question for consideration:}

1. What investigations can help to determine underlying etiology?

GO TO SECTION 3 


\section{Section 3}

Contrasted MRI of the brain showed small well-marginated multifocal areas of $\mathrm{T} 2$-weighted hyperintensity in the periventricular and frontoparietal subcortical white matter. These lesions did not demonstrate diffusion restriction, abnormal susceptibility, contrast enhancement, or surrounding vasogenic edema, and were likely ictal foci (figure 1). A lesion anterior to the left hand knob accounted for cortical myoclonus of the right upper limb.
An EEG was performed, which captured an electrographic seizure over the left hemisphere lasting 40 seconds. Bilateral independent periodic lateralized epileptiform discharges were recorded with background slowing.

Initial laboratory workup including a full blood count, basic metabolic and endocrine panel, and coagulation tests were unremarkable. Serology for HIV was negative.

\section{Questions for consideration:}

1. What is the differential diagnosis?

2. What additional tests would you order? 


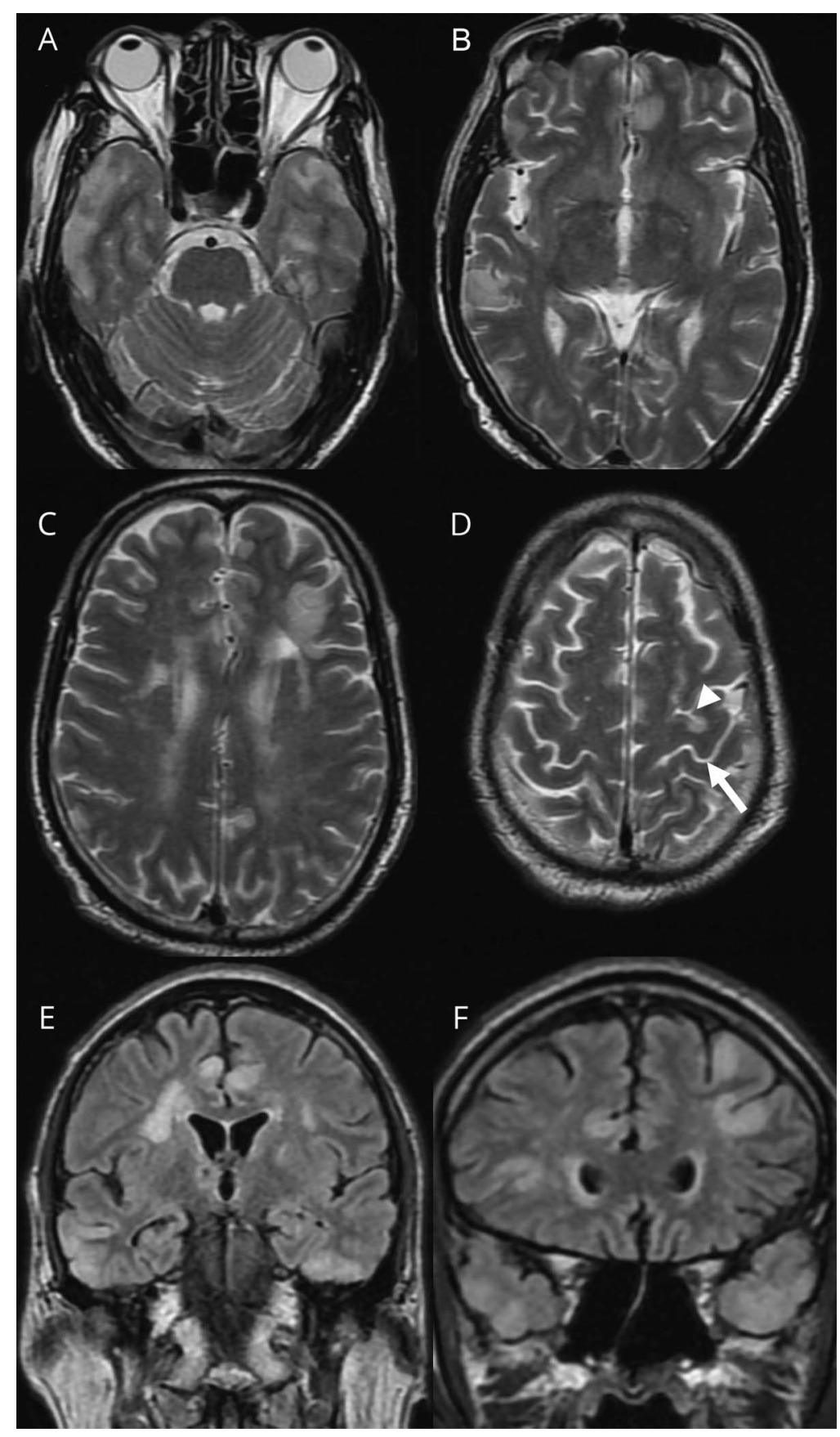

(A-D) Axial T2-weighted, (E-F) coronal T2 fluid-attenuated inversion recovery. Multifocal small well-marginated cortical and subcortical T2-weighted hyperintensities. There is no mass effect and no surrounding vasogenic edema. (D) The hand knob lies anterior to the indentation of the rolandic fissure (arrow). This represents the upper limb region of the primary motor cortex. Neuronal hyperexcitability arising from an area of T2-weighted hyperintensity anterior to the hand knob (arrowhead) probably resulted in cortical myoclonus of the right upper limb.

\section{GO TO SECTION 4}




\section{Section 4}

The differential diagnosis is broad and determination of the patient's immune status helps to narrow it. In the context of the case vignette, the absence of a history of immunosuppression, together with a negative HIV serology, suggest an immunocompetent state. The differential for an immunocompetent patient with acute onset of multifocal brain lesions includes vascular, infective, immune, and neoplastic causes.

Clinical and MRI features can help to further narrow the differential. Rapidly expanding brain lesions secondary to malignant, infective, or inflammatory causes are usually associated with surrounding mass effect and edema. This was not seen in our patient's lesions. In addition, the absence of restricted diffusion in the acute setting makes a vascular etiology less likely. The lesions were unlikely to be cerebral abscesses, which have hypointense centers with restricted diffusion, rimmed enhancement, and surrounding hypointense zone on postgadolinium $\mathrm{T} 1$ sequences. ${ }^{2}$ The presence of significant unintentional weight loss points to cerebral metastasis as a possibility. However, the acute nature of the neurologic presentation and the absence of contrast enhancement make malignancy less probable. ${ }^{3}$ Acute disseminated encephalomyelitis is usually seen in the setting of a prodromal illness and characteristic large globular diffuse marginated lesions can be found on imaging. ${ }^{4}$
The absence of myelopathy and optic neuritis put multiple sclerosis, neuromyelitis optica, and anti-myelin oligodendrocyte glycoprotein-related diseases further down the differential list. The absence of cranial neuropathies, hypothalamopituitary involvement, or leptomeningeal contrast enhancement argue against neurosarcoidosis.

CSF revealed $<4$ nucleated cells, $<1$ red blood cell, glucose 4 $\mathrm{mmol} / \mathrm{L}$, and protein of $0.31 \mathrm{~g} / \mathrm{L}$. CSF testing for herpes simplex virus, varicella-zoster virus, cytomegalovirus, toxoplasma, fungus, tuberculosis, and syphilis were negative. Flow cytometry was negative for lymphoma cells; cytologic examination was negative for malignant cells.

Serum examination of antinuclear antibodies, antineutrophil cytoplasmic antibodies, anti-Ro, anti-La, and anti-glutamate decarboxylase (GAD) were negative. Antibodies against NMDA, contactin-associated protein 2, leucine-rich, glioma inactivated 1 , $\alpha$-amino-3-hydroxy-5-methyl-4-isoxazolepropionic acid (AMPA), and dipeptidyl-peptidase-like protein 6 were not detected.

CT imaging of the chest, abdomen, and pelvis showed a solid anterior mediastinal mass, suggestive of thymic neoplasm (figure 2).

\section{Questions for consideration:}

1. What is the diagnosis?

2. How would you treat the patient? 
Figure 2 CT chest, abdomen, and pelvis

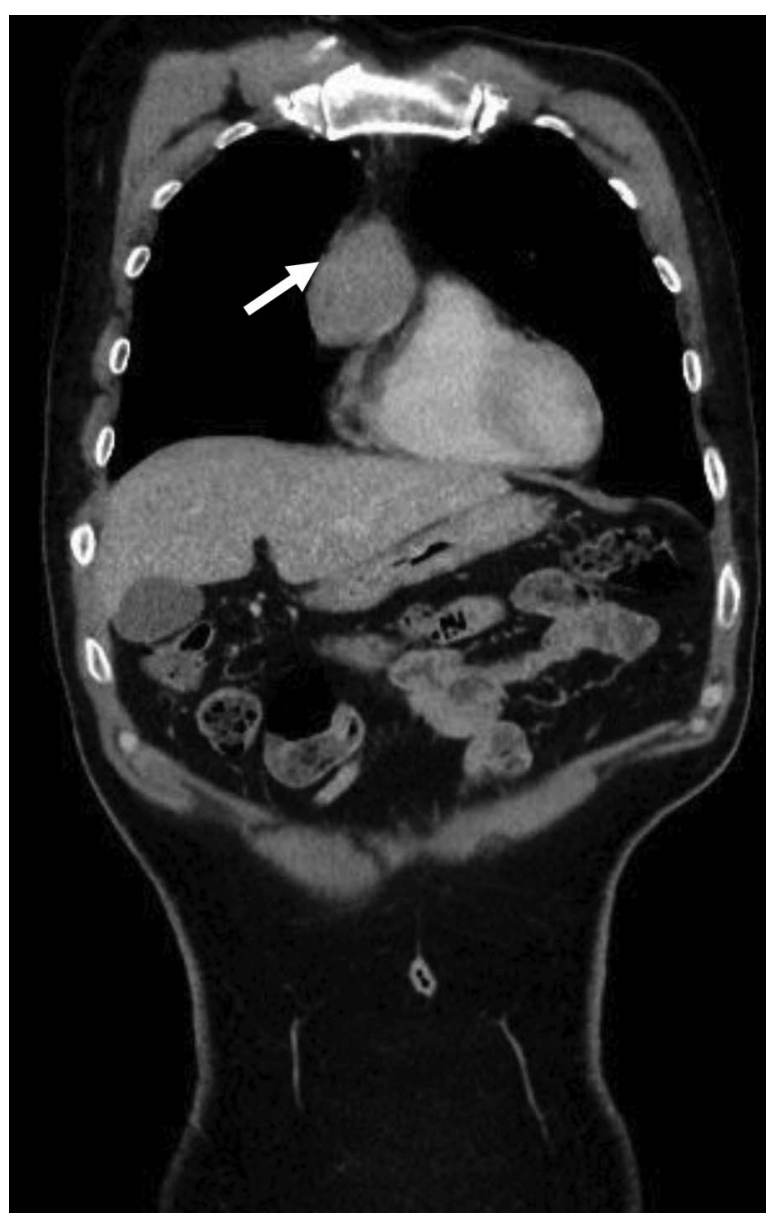

Solid anterior mediastinal mass (arrow) suggestive of a thymic neoplasm.

\section{GO TO SECTION 5}




\section{Section 5}

A diagnosis of extralimbic paraneoplastic autoimmune encephalitis secondary to underlying thymoma was made. This was complicated by complex partial seizures, cortical myoclonic jerks, and encephalopathy. As the suspicion for anti-GABA $A_{A}$ receptor $\left(G A B A_{A} R\right)$ encephalitis was high, the patient's serum specimen was sent for further testing (autoimmune neurology laboratory, University of Oxford, UK). This subsequently returned weakly positive. CSF analysis for $\mathrm{GABA}_{\mathrm{A}} \mathrm{R}$ antibody was not performed.

The patient's seizures became increasingly difficult to control and he remained in an encephalopathic state. Multiple antiepileptic agents and subsequently anesthetic agents were initiated. He received pulsed IV methylprednisolone followed by high-dose corticosteroid treatment. He also underwent 5 cycles of plasma exchange when initial pulsed corticosteroid therapy failed to yield substantial clinical improvement. Robotic assisted surgical resection of the thymoma was performed 2 weeks into admission. Histology showed mixed type B2 and type B3 thymoma with several foci of transcapsular invasion. Full course of adjuvant radiotherapy was completed subsequently.

The patient had a complicated inpatient intensive care unit (ICU) and subsequent inpatient hospital stay. Multiple complications including drug-induced hepatotoxicity, acute drug-induced kidney injury, disseminated multidrug-resistant Acinetobacter baumannii infection, and cryptococcal meningitis requiring prolonged IV antibiotics occurred.

Seizures eventually remitted and the patient's conscious level improved. Repeat MRI brain showed partial resolution of prior brain lesions. He was discharged at baseline cognitive function 10 months from onset of symptoms and remains in remission and is seizure-free 16 months from onset of symptoms. He is currently on low-dose maintenance corticosteroids as well as low-dose levetiracetam.

\section{Discussion}

The $\mathrm{GABA}_{\mathrm{A}} \mathrm{R}$ is a ligand-gated ion channel that modulates fast inhibitory synaptic transmission in the brain. ${ }^{5}$ Autoimmunity against $\mathrm{GABA}_{\mathrm{A}} \mathrm{R}$ was first reported in $2014 .{ }^{6}$ It is suggested that the binding of $G_{A B A_{A}} R$ antibodies to $\mathrm{GABA}_{\mathrm{A}} \mathrm{R}$ causes the relocation of $\mathrm{GABA}_{\mathrm{A}} \mathrm{R}$ from the synaptic membrane. Together with status epilepticus-induced loss of $\mathrm{GABA}_{\mathrm{A}} \mathrm{R}$, these 2 factors result in increased neuronal excitability and is the postulated reason behind the refractory nature of seizures in this condition. ${ }^{5}$

Our patient's clinical picture is consistent with that reported in a large case series of 26 patients. ${ }^{7}$ Patients typically present with rapidly progressive encephalopathy with refractory status epilepticus. Concomitant movement disorders including orofacial dyskinesia, dystonia, choreoathetosis, facial twitches, and cramps have been described. Cortical myoclonus has not previously been reported.

Anti-GABA $A_{A} R$ encephalitis is associated with a coexisting neoplastic process in $40 \%$ of patients, with thymomas being the most common associated neoplasm.

$\mathrm{GABA}_{\mathrm{A}} \mathrm{R}$ antibody testing is not routinely included in autoimmune encephalitis panels of many laboratories; hence MRI brain findings provide vital clues to the diagnosis and guide the investigations. Typical MRI findings comprise multifocal cortical-subcortical T2/fluid-attenuated inversion recovery hyperintensities. Patients with anti-AMPAR encephalitis and anti-GAD encephalitis may occasionally have similar imaging findings. ${ }^{8,9}$ Such MRI brain findings are rarely seen in other forms of autoimmune encephalitis and in other etiologies. On the other hand, CSF and EEG findings can be nonspecific. CSF is normal in $42 \%$ of patients and EEG typically reveals epileptiform activity. Antibody positivity may occur in either CSF or serum, hence testing both CSF and serum is suggested. ${ }^{7}$

Randomized, controlled treatment trials for $\mathrm{GABA}_{\mathrm{A}} \mathrm{R}$ and other autoimmune encephalitides are not available. Treatment is guided by observational studies as well as expert opinion. ${ }^{10}$ Patients frequently require ICU admission and aggressive treatment with immunotherapy, antiepileptic treatment, and tumor resection. High-dose pulse IV corticosteroids followed by high-dose maintenance corticosteroids are used as first-line treatment. IV immunoglobulin can be considered when corticosteroids are contraindicated. Plasma exchange can be considered in patients who have severe attacks or demonstrate incomplete response to corticosteroid treatment. Second-line therapy in the form of IV rituximab or cyclophosphamide can be used in refractory cases. With aggressive treatment, a substantial proportion of patients can make partial to complete recovery, as in the patient in our vignette. Prompt recognition of this condition is therefore important.

\section{Study funding}

No targeted funding reported.

\section{Disclosure}

The authors report no disclosures relevant to the manuscript. Go to Neurology.org/ $\mathrm{N}$ for full disclosures.

Appendix 1 Author contributions

\begin{tabular}{llll}
\hline Name & Location & Role & Contribution \\
\hline $\begin{array}{l}\text { Zhiyong Chen, } \\
\text { MBBS, MRCP }\end{array}$ & $\begin{array}{l}\text { National Neuroscience } \\
\text { Institute, Singapore }\end{array}$ & Author & $\begin{array}{l}\text { Acquisition of } \\
\text { data, writing of } \\
\text { manuscript }\end{array}$ \\
\hline $\begin{array}{l}\text { Shermyn Neo, } \\
\text { MBBS, MRCP }\end{array}$ & $\begin{array}{l}\text { National Neuroscience } \\
\text { Institute, Singapore }\end{array}$ & Author & $\begin{array}{l}\text { Writing of } \\
\text { manuscript }\end{array}$ \\
\hline
\end{tabular}




\section{References}

1. Kojovic M, Cordivari C, Bhatia K. Myoclonic disorders: a practical approach for diagnosis and treatment. Ther Adv Neurol Disord 2011;4:47-62.

2. Brouwer MC, Tunkel AR, McKhann GM, van de Beek D. Brain abscess, N Engl J Med 2014;371:447-456.

3. Lu-Emerson C, Eichler AF. Brain metastases. Continuum 2012;18:295-311.

4. Pohl D, Alper G, Van Haren K, Kornberg AJ, Belman AL. Acute disseminated encephalomyelitis: updates on an inflammatory CNS syndrome. Neurology 2016;87(suppl 2):S38-S45.

5. Quek AML, O'Toole O. Encephalitis associated with autoantibodies binding to $\gamma$-aminobutyric acid-A, $\gamma$-aminobutyric acid-B and glycine receptors: immunopathogenic mechanisms and clinical characteristics. Neuroimmunol Neuroinflamm 2016;3:86-92.
6. Petit-Pedrol M, Armangue T, Peng X, et al. Encephalitis with refractory seizures, status epilepticus, and antibodies to the GABAA receptor: a case series, characterisation of the antigen, and analysis of the effects of antibodies. Lancet Neurol 2014;13:276-286.

7. Spatola M, Petit-Pedrol M, Simabukuro MM, Armangue T, Dalmau J. Investigations in GABAA receptor antibody-associated encephalitis. Neurology 2017;88:1012-1020.

8. Höftberger R, van Sonderen A, Leypoldt F, Houghton D, Dalmau J. Encephalitis and AMPA receptor antibodies: novel findings in a case series of 22 patients. Neurology 2015;84:2403-2412.

9. Najjar S, Pearlman D, Najjar A, Ghiasian V, Zagzag D, Devinsky O. Extralimbic autoimmune encephalitis associated with glutamic acid decarboxylase antibodies: an underdiagnosed entity? Epilepsy Behav 2011;21:306-313.

10. McKeon A. Autoimmune encephalopathies and dementias. Continuum 2016;22: $538-558$. 


\section{Neurology}

\section{Clinical Reasoning: A middle-aged man with new onset seizures and myoclonic jerks Zhiyong Chen and Shermyn Neo \\ Neurology 2019;92;e274-e281 \\ DOI 10.1212/WNL.0000000000006781}

This information is current as of January 14, 2019

\section{Updated Information \& Services}

References

Citations

Subspecialty Collections

Permissions \& Licensing

Reprints including high resolution figures, can be found at: http://n.neurology.org/content/92/3/e274.full

This article cites 10 articles, 2 of which you can access for free at: http://n.neurology.org/content/92/3/e274.full\#ref-list-1

This article has been cited by 2 HighWire-hosted articles: http://n.neurology.org/content/92/3/e274.full\#\#otherarticles

This article, along with others on similar topics, appears in the following collection(s):

Autoimmune diseases

http://n.neurology.org/cgi/collection/autoimmune_diseases

Complex partial seizures

http://n.neurology.org/cgi/collection/complex_partial_seizures

MRI

http://n.neurology.org/cgi/collection/mri

Myoclonus

http://n.neurology.org/cgi/collection/myoclonus

Information about reproducing this article in parts (figures,tables) or in its entirety can be found online at:

http://www.neurology.org/about/about_the_journal\#permissions

Information about ordering reprints can be found online:

http://n.neurology.org/subscribers/advertise

Neurology ${ }^{\circledR}$ is the official journal of the American Academy of Neurology. Published continuously since 1951, it is now a weekly with 48 issues per year. Copyright (O 2019 American Academy of Neurology. All rights reserved. Print ISSN: 0028-3878. Online ISSN: 1526-632X.

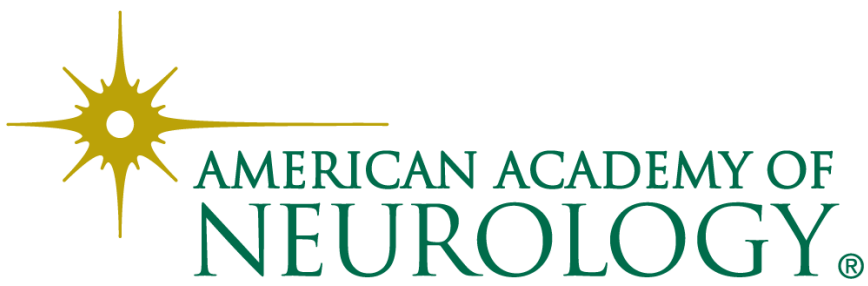

